University of Nebraska - Lincoln

DigitalCommons@University of Nebraska - Lincoln

Robert Katz Publications

Research Papers in Physics and Astronomy

November 1961

\title{
Transverse Mass and Gravitational Mass
}

Robert Katz

University of Nebraska-Lincoln, rkatz2@unl.edu

Follow this and additional works at: https://digitalcommons.unl.edu/physicskatz

Part of the Physics Commons

Katz, Robert, "Transverse Mass and Gravitational Mass" (1961). Robert Katz Publications. 42.

https://digitalcommons.unl.edu/physicskatz/42

This Article is brought to you for free and open access by the Research Papers in Physics and Astronomy at DigitalCommons@University of Nebraska - Lincoln. It has been accepted for inclusion in Robert Katz Publications by an authorized administrator of DigitalCommons@University of Nebraska - Lincoln. 
Published in American Journal of Physics (November 1961) Volume 29, Issue 11, pp. 786-787

\title{
Transverse Mass and Gravitational Mass
}

\author{
Robert Katz \\ Kansas State University, Manhattan, Kansas
}

\begin{abstract}
A problem suggested by Professor Gamow deals with the relationship between the transverse mass and the gravitational mass: A steamroller of mass $m$ moves horizontally, in the $+x$ direction, with velocity $v$, in a region of space in which there is a gravitational field intensity $g$ vertically downward. Find the weight of the moving steamroller.
\end{abstract}

C01961 American Association of Physics Teachers

doi:10.1119/1.1937597

Online at http://scitation.aip.org/dbt/dbt.jsp?KEY=AJPIAS\&Volume=29\&Issue=11 


\title{
Transverse Mass and Gravitational Mass
}

RoBERT KATZ

Kansas State University, Manhahtan, Karsas

\begin{abstract}
A PROBLEM suggested by Professor Gamow deals $A$ with the relationship between the transverse mass and the gravitational mass: A steamroller of mass $m$ moves horizontally, in the $+x$ direction, with velocity $v$, in a region of space in which there is a gravitational field intensity $g$ vertically downward. Find the weight of the moving steamroller.

Following Schiff. we assert that gravitational effects can be incorporated into special relativity by use of the equivalence principle, and that accelerations do not affect the applicability of the Lorentz transformations. Consider three observers: $A$ is at rest in the gravitational field, $B$
\end{abstract}


is on a second frame in field free space which is accelerated upward ( $+z$ direction) with acceleration $g$ with respect to an inertial frame on which observer $C$ is located. By the equivalence principle, $B$ is equivalent to $A$. We consider a steamroller of mass $m_{0}$ which is moving in the $x$ direction with velocity $v$ in $B$ 's frame. The steamroller is observed by inertial observer $C$ for whom it is instantaneously at rest in the $z$ direction but is accelerated with acceleration $g$.

$C$ knows that in first approximation Newtonian mechanics is correct, but that he must amend it for transverse accelerations by use of the transverse mass. He infers that the steamroller must be experiencing an upward force $F_{z}=m_{0} g /\left(1-v^{2} / c^{2}\right)^{\frac{z}{2}}$. Since $B$ is instantaneously at rest with respect to $C$ he agrees with $C$ 's conclusion. And since $B$ is equivalent to $A, A$ must conclude that the weight of a moving steamroller is determined by its transverse mass in this case, rather than by its rest mass. That is, a steamroller moving in the horizontal direction with speed $v$ weighs $m_{0} g /\left(1-v^{2} / c^{2}\right)^{\frac{3}{2}}$ instead of $m_{0} g$ which it weighed when at rest.

1 L. I. Schiff, Am. J. Phys. 28, 340 (1960). 